1 Fundação Oswaldo Cruz (Fiocruz), Escola Nacional de Saúde Pública Sergio Arouca (Ensp) - Rio de Janeiro (RJ), Brasil. m.crisjc@gmail.com

2 Fundação Oswaldo Cruz (Fiocruz), Escola Nacional de Saúde Pública Sergio Arouca (Ensp), Departamento de Direitos Humanos, Saúde e Diversidade de Cultural (DIHS) - Rio de Janeiro (RJ), Brasil.

mhelen@ensp.fiocruz.br

3 Fundação Oswaldo Cruz (Fiocruz), Escola Naciona de Saúde Pública Sergio Arouca (Ensp), Centro de Estudos da Saúde do Trabalhador e Ecologia Humana (Cesteh) - Rio de Janeiro (RJ), Brasil.

renato.bonfatti@gmail.com

\section{O processo de institucionalização das práticas de saúde em uma unidade de produção da Fiocruz}

\author{
The process of institutionalization of health practices in a production \\ unit of Fiocruz
}

Maria Cristina Jorge de Carvalho', Maria Helena Barros de Oliveira², Renato José Bonfatti ${ }^{\mathbf{3}}$

RESUMO O artigo apresenta o resgate do processo de institucionalização das práticas de saúde em uma unidade da Fundação Oswaldo Cruz (Fiocruz) compreendendo as distintas abordagens das relações saúde-trabalho. Trata-se de estudo de caso desenvolvido por meio de pesquisa documental e entrevistas semiestruturadas, utilizando análise de conteúdo. Constatam-se dificuldades em adequar as formas de regular o trabalho com os princípios do campo da Saúde do Trabalhador devido à carência de integração de ações, uniformização técnica e troca de saberes. Conclui-se que há necessidade de políticas institucionais favorecendo espaços para ampla participação dos trabalhadores em todos os processos para o cuidado de sua saúde e segurança.

PALAVRAS-CHAVE Saúde do trabalhador. Promoção da saúde. Institutos governamentais de pesquisa.

ABSTRACT The article presents the rescue of the process of institutionalization of health practices in a unit of Oswaldo Cruz Foundation (Fiocruz), comprising the different approaches of health-work relations. It is a case study developed through documentary research and semistructured interviews, using content analysis. Difficulties are found in adapting ways to regulate work with the principles of the field of Occupational Health due to the lack of integration of actions, technical standardization and exchange of knowledge. It is concluded that there is a need for institutional policies favoring spaces for the broad participation of workers in all processes for the care of their health and safety.

KEYWORDS Occupational health. Health promotion. Governmental research institutes. 


\section{Introdução}

Ao longo da história recente das políticas de saúde brasileiras, a questão da saúde do trabalhador foi afirmada como problema de saúde pública. Conforme Vasconcellos (2011), tal afirmação foi inscrita constitucionalmente enquanto um campo político e ideológico norteador para as práticas de saúde no trabalho, entretanto sua concretização nessa perspectiva permanece um desafio. No âmbito empresarial, seja no serviço público ou não, os serviços de saúde no trabalho desenvolvem programas com o cunho gerencialista e pragmático da iniciativa privada. De acordo com Minayo-Gomes e Thedim-Costa (1997), as razões são calcadas por princípios econômicos, e não por princípios genuinamente ancorados na saúde dos que trabalham.

O objeto do estudo foram as práticas de saúde em uma unidade de produção da Fundação Oswaldo Cruz (Fiocruz). Observou-se que as práticas implementadas são perpassadas por diferentes abordagens para lidar com as questões da relação trabalho-saúde. Destacam-se as atribuições da Medicina do Trabalho (MT) e da Engenharia e Segurança do Trabalho, configurando-se nas práticas da Saúde Ocupacional (SO) preconizadas na legislação trabalhista, e a Saúde do Trabalhador (ST) enquanto uma diretriz conceitual e ideológica, inscrita na política pública de saúde. Além das duas abordagens, o Programa de Qualidade de Vida (PQV) se sobressai acompanhando uma perspectiva geracional que o concebe como instrumento de gestão como apresentado por Ferreira (2006), Ferreira, Alves e Tostes (2009), Limongi-França e Zaima (2002). Apesar das práticas do $\mathrm{PQV}$ e dos paradigmas da $\mathrm{SO}$ e ST atuarem na perspectiva da promoção e prevenção dos danos à saúde, Vasconcellos (2011) pontua que as abordagens possuem diferenças conceituais, ideológicas e normativas, que delimitam cada campo de atuação e dificultam atividades integralizadoras.

$\mathrm{O}$ estudo buscou compreender os fatores que favorecem o distanciamento entre as práticas de saúde implementadas e o que é preconizado pelos conceitos do campo da ST. Tais conceitos priorizam o trabalhador como sujeito e agente essencial para as mudanças dos processos e práticas causadores de danos à saúde. Assim, buscou-se resgatar o processo histórico de implementação e implantação do Serviço de Saúde do Trabalhador da unidade em seus aspectos organizacionais e operacionais compreendendo as influências das distintas abordagens das relações saúde-trabalho e quais os avanços e desafios para o serviço na perspectiva da ST. Os objetivos específicos foram: 1) Contextualizar o processo de implementação e implantação do Serviço de Saúde do Trabalhador em uma unidade de produção da Fiocruz; 2) Descrever as práticas implementadas; 3 ) Analisar os avanços e desafios; 4) Propor ações sob a perspectiva do campo da ST; 5) Contribuir para as reflexões do campo da ST no âmbito organizacional.

\section{Material e métodos}

A pesquisa de caráter qualitativo e exploratório delineou-se em um estudo de caso. Foi realizado levantamento de 25 documentos institucionais sobre a implantação, a operacionalização e a organização do serviço de saúde da unidade. Os documentos analisados foram: relatórios institucionais, manual da organização, projeto de implantação do serviço; descrição de serviços, além de consultas às informações disponíveis no Portal Corporativo e site da unidade. Além disso, foram realizadas 17 entrevistas semistruturadas com atores-chave que fizeram parte da construção da área de ST na Fiocruz e na unidade específica do estudo. Os critérios para inclusão foram definidos a partir da identificação dos atores-chave que participaram do processo de implantação e implementação do serviço.

O projeto tramitou no Comitê de Ética 
e Pesquisa e recebeu parecer favorável de número 1.073 .776 em 5 de maio 2015. Todos os entrevistados receberam convite prévio e assinaram o Termo de Consentimento Livre e Esclarecido (TCLE). As entrevistas foram gravadas e transcritas, e os dados, analisados por meio da análise de conteúdo. De acordo com Bardin (2009), tal método pretende fornecer técnicas precisas e objetivas suficientes para garantir a descoberta do verdadeiro significado. $\mathrm{O}$ objeto nesse método é a palavra, o que permite de forma objetiva e prática a produção de inferências do conteúdo do texto. Buscou-se categorizar as palavras ou frases que se repetiram, depreendendo a uma expressão representativa. Assim, por meio de características construídas e definidas a partir das significações ou temas que emergiram no texto, verificou-se o que possuíam em comum, obtendo-se agrupamentos temáticos.

A análise se debruçou sobre a exploração de um conjunto de opiniões e percepções dos atores-chave objetivando atribuir sentido ao mosaico de informações, tendo como referência os pressupostos teóricos. O percurso utilizado confere o modus operandi da análise de conteúdo: 1) pré-análise, 2) exploração do material e 3) tratamento dos resultados, inferência e interpretação.

\section{Resultados e discussão}

A ST surge enquanto campo de conhecimento na transição democrática do Brasil, a partir do final da década de 1970 e início dos anos 1980, sob forte influência no âmbito nacional do movimento sindical e da universalização da saúde, conforme Lacaz (2000), Tambellini, Almeida e Câmara (2013). No âmbito internacional, recebeu a influência da Medicina Social Latino-Americana e do Movimento Operário Italiano (MOI). A organização dos operários na Reforma Sanitária Italiana foi marcada pelas reivindicações para ampliação dos direitos à saúde no trabalho e pelo controle da nocividade do trabalho, citados por Minayo-Gomez, Machado e Pena (2011); Paiva e Vasconcellos (2011).

Os debates configuraram o denominado MOI, o qual

foi uma das iniciativas mais significativas que influenciou e redirecionou o debate sobre 0 campo das relações saúde-trabalho no século XX. (PAIVA; VASCONCELLOS, 2011, P. 357).

O modelo, portanto, propõe uma metodologia que tem entre seus princípios que o trabalhador, e não o especialista, identifique e avalie os fatores e os efeitos nocivos da sua situação no trabalho. Concebe o trabalhador como sujeito do processo. Cavalcanti (2011) ressalta que, ao buscar uma atuação democrática, valoriza-se o conhecimento dos trabalhadores, e os saberes são compartilhados, colocando a técnica a serviço dos trabalhadores.

O discurso da ST surge em contraposição às bases conceituais e práticas da $\mathrm{MT}$ e da SO, concepções das relações trabalho e saúde consideradas hegemônicas. No contexto brasileiro essa hegemonia se solidificou devido à própria ação do Estado que, por meio do setor trabalho, embasado em teorias científicas universais, institucionalizou, durante o Regime Militar, uma política baseada no discurso da técnica articulada às relações de poder e ao disciplinamento do trabalhador, passando a exigir, na década de 1970, a criação dos Serviços Especializados em Engenharia de Segurança e Medicina do Trabalho (SESMT), delegando às empresas a tutela da saúde dos trabalhadores. De acordo com Lacaz (2000, P. 760), "tal política visa a aumentar a produtividade e a saúde tem caráter de razão instrumental para a produção".

Essa exigência foi determinada na Norma Regulamentadora $\mathrm{n}^{\circ} 4$ (NR 4) do Ministério do Trabalho e Emprego (MTE) ao informar sobre a obrigatoriedade das empresas privadas e públicas, dos órgãos públicos da administração direta e indireta e dos poderes 
Legislativo e Judiciário, que possuam empregados regidos pela CLT, de manterem SESMT, com a finalidade de promover a saúde e proteger a integridade do trabalhador no local de trabalho.

A Saúde Ocupacional, do ponto de vista disciplinar e profissional abrange fundamentalmente as áreas de medicina e engenharia de segurança, restringindo-se a dimensão contratual das empresas. (MINAYO-GOMEZ, 2011, P. 25).

Os instrumentos para o cumprimento das exigências normativas, de forma geral, são utilizados de forma restrita e limitados, em que aspectos como processo e organização do trabalho não são considerados.

Vasconcellos (2011) menciona que há no Brasil um dualismo entre ST e SO já cristalizado. Essas duas expressões das relações saúde e trabalho convivem e coexistem no cumprimento das regras sobre a saúde no trabalho. Entretanto, há dificuldades na realização de ações integralizadoras, decorrente das diferenças conceituais e ideológicas gerando divergências e conflitos. O mesmo autor ressalta que, ao superar a visão da SO, a ST se situa na perspectiva da saúde como direito, conforme foi inscrita no Sistema Único de Saúde (SUS) no que se refere aos direitos fundamentais.

Com as transformações do mundo do trabalho ocasionadas a partir da década de 1980, conforme Antunes (2008); Franco, Druck e Seligmann-Silva (2010); Mota e Amaral (2010) a 'flexibilização' das relações de trabalho introduz novas formas de contratação de mão de obra. Há um alto número de contratações de mão de obra terceirizada ocorrendo diferenças salariais, mesmo exercendo atribuições iguais. Pina e Stotz (2014) abordam que o trabalho polivalente é cada vez mais utilizado com objetivo de haver um revezamento de tarefas e postos de trabalho e otimizar o uso intensivo da força de trabalho.

De acordo com Ferreira, Alves e Tostes (2009), em decorrência desse cenário e da adoção de novas práticas organizacionais, já a partir da década de 1970, a Qualidade de Vida no Trabalho (QVT) passou a ser um objeto de preocupação e de investimento, sobretudo, nas grandes corporações. No bojo dessa nova lógica, surgem os Programas de QVT sendo sua abordagem utilizada enquanto uma ferramenta de gestão buscando elevar a motivação, satisfação e saúde.

Para Ferreira (2006), o que os trabalhadores necessitam é que haja a eliminação ou a atenuação dos fatores crônicos do desgaste e mal-estar, reduzindo o estresse ocupacional. $\mathrm{O}$ autor menciona que é necessária a implementação de um Programa de QVT de natureza preventiva. Na visão de Lacaz (2000), o que interessa é discutir a vertente que prioriza as condições, ambientes, organização do trabalho e as tecnologias preconizando maior participação dos trabalhadores nas decisões. É plausível que os programas de QVT busquem uma atuação mais abrangente e efetiva, essencialmente fortalecendo a discussão das condições de trabalho e a qualidade das relações de trabalho, relacionando com as repercussões na saúde dos trabalhadores e os impactos na própria organização.

\section{Cenário}

A Fiocruz é uma organização de ciência e tecnologia em saúde responsável pela realização de pesquisa, desenvolvimento tecnológico, educação no campo da saúde, serviços de saúde, além da produção de insumos estratégicos para o SUS. É composta por unidades técnico-científicas, que foram incorporadas à Fiocruz desde a década de 1970 e que compõem atualmente uma única organização, complexa, múltipla, diversa e singular no campo da saúde.

A unidade em estudo tem como principal atividade a produção de vacinas para o uso humano, visando atender prioritariamente à demanda nacional por intermédio do Ministério da Saúde (MS). Sua missão é contribuir para a melhoria dos padrões de 
saúde pública brasileira, por meio de inovação, desenvolvimento tecnológico, produção de imunobiológicos e prestação de serviços. Para tanto, a unidade necessita estabelecer transferências de tecnologias, buscando inovação na forma de gerir e produzir, necessitando de ampla estrutura na adequação de novos processos e atendimento aos critérios dos órgãos regulamentadores para atender à crescente necessidade de produção de vacinas e biofármacos, em especial para o Programa Nacional de Imunização (PNI) do MS, que estabeleceu as dimensões da demanda do Programa de Autossuficiência Nacional em Imunobiológicos (Pasni). Este programa implicou o aumento da capacidade da oferta interna, da qualidade e esforço de redução da dependência externa, melhoria da qualidade da produção e busca da autossuficiência na produção das vacinas essenciais. A fabricação de vacinas tem sua atividade regulada pelo poder público, por meio da Agência Nacional de Vigilância Sanitária (Anvisa), e é submetida a uma série de práticas e controles que visam assegurar uma produção com padrões de qualidade.

$\mathrm{Na}$ esteira das práticas organizacionais atuais, a unidade se caracteriza em uma indústria com gestão pública no contexto da reestruturação produtiva em que se observa formas de gestão empresarial como a multifuncionalidade, a redução de pessoal, a multiplicidade de vínculos, a intensificação do ritmo de trabalho, as estratégias para o cumprimento de metas e adequação de indicadores, a ênfase no espírito de equipe e do discurso do trabalhador 'colaborador', o controle de frequência por meio de ponto eletrônico e a utilização de banco de horas, além da implementação de $\mathrm{PQV}$, entre outras.

\section{Processo histórico}

A Reforma Sanitária na década de 1980 levou para a pauta das discussões a questão de um modelo inovador, diferente da MT e da SO. Naquele momento, a Fiocruz foi uma instituição que mobilizou e proporcionou grandes debates nesse contexto. Esses debates fortaleceram a concepção do SUS e a obrigação do Estado sobre a saúde e, especificamente, sobre saúde do trabalhador. Em 1985, foi criado na Escola Nacional de Saúde Pública (Ensp/Fiocruz) o Centro de Estudos em Saúde do Trabalhador e Ecologia Humana (Cesteh), com o objetivo de realizar pesquisas, estudos e assistência, para o público externo, referenciado pela rede do SUS (Ator-chave 2).

Começou-se a pensar em um serviço que pudesse atender às demandas de saúde dos trabalhadores da instituição, sendo criado o Serviço de Atenção à Saúde do Trabalhador (FioSAST), este sendo a primeira experiência institucional para atender as demandas dos trabalhadores de toda a Fiocruz. Mais tarde, foi criado o Núcleo de Saúde do Trabalhador (Nust-Fiocruz) e a Coordenação de Saúde do Trabalhador (CST) que ficaria no âmbito da presidência, com a possibilidade de coordenar toda a Fiocruz. (Ator-chave 3).

Percebe-se que, no processo de construção da ST no âmbito da Fiocruz, aquilo que foi idealizado em sua origem e concepção sofreu uma série de dificuldades, sobretudo políticas. Conforme Minayo et al. (1998), levar à frente um projeto articulando os diversos saberes para dar conta da complexidade dos diferentes modos de trabalhar, na perspectiva do conceito que foi forjado no interior dessa instituição, foi e permanece sendo um desafio.

Para aumentar a capacidade produtiva, em 1990, houve o start do projeto da planta industrial do Complexo Tecnológicos de Vacinas (CTV), inicialmente com o Departamento de Processamento Final (DEPFI). Este departamento foi construído para a realização de todo o processamento final da produção de vacinas, realizando os processos: envase, liofilização, rotulagem e embalagem.

O processo de terceirização se iniciou a partir de 1994, ante o aumento das demandas inerentes às áreas da qualidade, produção 
e desenvolvimento de tecnologias. A partir disso, o contingente de trabalhadores terceirizados aumentou a cada ano, sendo hoje o equivalente a $80 \%$ dos trabalhadores vinculados à unidade. Em 1997, houve a implantação de um novo modelo de gestão na unidade, focado em avaliação de resultados, autonomia, autossustentabilidade, agilidade e flexibilidade operacional. Houve também o estabelecimento de um termo de compromisso de gestão entre a Fiocruz e a unidade e de uma nova estrutura organizacional (Ator-chave 11).

Anteriormente ao processo de pensar em criar um serviço de atenção à saúde na unidade, buscou-se uma assessoria da Coordenação de Saúde do Trabalhador (CST) para a implantação da Engenharia e Segurança do Trabalho. "Era necessário um projeto de Engenharia de Segurança baseado nos critérios internacionais" (Ator-chave 3). Devido a essa interlocução e influência da CST, a Engenharia de Segurança buscou, naquela época, uma atuação na perspectiva da ST, "superando um olhar estritamente tecnicista, adotando uma visão ampla com diálogos com os trabalhadores" (Ator-chave 12).

O Serviço de Saúde do Trabalhador foi implantado em 2008 com uma pretensão de ser um braço do Nust-Fiocruz para atender os trabalhadores da unidade e adequar as exigências de inspeções regulatórias. A constituição de um serviço possibilitaria uma avaliação mais aproximada e a compreensão dos problemas em relação a processos de trabalho, além de possibilitar o atendimento em casos de acidentes de uma forma mais rápida. O serviço recebeu diferentes nomenclaturas, que, por suas diferenças conceituais, trazem algumas questões do ponto de vista teórico-prático ocasionando, na concepção de alguns, como que uma 'crise de identidade'. A utilização oficial de Seção de Medicina do Trabalho não retrata a realidade do trabalho desenvolvido, pois existe, ainda que com fragilidades, uma equipe multidisciplinar. "Essa denominação constitui um retrocesso diante da concepção de ST e do próprio trabalho que se busca desenvolver" (Ator-chave 7).

Além disso, ao ser constituído, ficou separado hierarquicamente do setor de Engenharia e Segurança do Trabalho. A NR 4 determina que ambas as especialidades devem atuar em conjunto na busca da proteção à saúde dos trabalhadores. Entretanto, por uma questão cultural, no campo empresarial, a área da saúde, em geral, é ligada à área de recursos humanos. As explicações para a configuração dessa separação passam pelo entendimento das necessidades apresentadas no decorrer histórico. Compreende-se que a área de Segurança do Trabalho tem características diferentes da área de ST.

E naquela época a concepção que se tinha é que deveriam ser setores distintos. Essa separação se configura uma dicotomia, com interesses distintos, enfraquecendo as ações na concepção da ST, a qual por sua importância deveria estar em um patamar estratégico na unidade, considerando o papel social da instituição enquanto modelo de práticas para a Saúde Coletiva. (Ator-chave 12).

Verifica-se que essa separação em hierarquias distintas provoca alguns impasses operacionais que atrapalham o desenvolvimento de um trabalho em uma perspectiva multiprofissional e interdisciplinar que possibilite a intervenção nos ambientes e processos de trabalho com a uniformização de saberes e um alinhamento nas concepções.

Além das atribuições distintas definidas pela hierarquização, entre os motivos, está à percepção de haver visões diferentes e uma perspectiva de ação divergente entre a ST e a Engenharia e Segurança do Trabalho.

Essa dificuldade ocorre devido à própria formação, onde não há uma formação de saúde coletiva nas universidades de maneira a formar profissionais com essa perspectiva. No campo empresarial, essa dificuldade é maior devido à lógica das empresas, onde a maioria dos profissionais atua sob uma perspectiva reducionista e pragmática. (Ator-chave 3). 
É apontada uma deficiência nos diálogos e pouca interação, constatando dificuldades para atuar em conjunto devido a divergências de opiniões e visões.

Tais divergências ocorrem devido às perspectivas diferentes de se perceber as questões de Saúde e Segurança no âmbito institucional, pois não há um alinhamento para a apreensão do conceito de ST. (Ator-chave 4).

\section{Práticas de saúde}

Após iniciado o processo de terceirização, em 2000, a Comissão Interna de Prevenção de Acidentes (Cipa) foi implantada conforme preconizado na NR 5, sendo composta por trabalhadores da empresa prestadora. "Desde sua implantação é organizada pela equipe da Segurança do Trabalho e atua em parceria com o serviço de ST" (Ator-chave 10). Destaca-se, como importante instrumento elaborado pela Cipa, o mapa de riscos, que é construído a partir da percepção dos trabalhadores e tem como finalidade a prevenção dos acidentes, a identificação dos riscos, visando encontrar soluções para eliminar ou controlar riscos e, consequentemente, melhorar as condições de trabalho. Atuando nessa perspectiva, o instrumento seria um potente canal para ampliação das possibilidades de mudança e troca de saberes, proporcionando ampla participação dos trabalhadores para conhecimento e tratamento das questões relacionadas com à saúde e segurança no trabalho.

O Programa de Prevenção de Riscos Ambientais (PPRA) visa à preservação da saúde, à segurança e à integridade dos trabalhadores, por meio da antecipação, reconhecimento, avaliação e, consequentemente, o controle da ocorrência de riscos ambientais existentes no ambiente de trabalho. Faz parte do conjunto de iniciativas de caráter obrigatório das empresas que deve estar articulado a outras normas como o Programa de Controle Médico e Saúde Ocupacional (PCMSO). "É realizado anualmente para uma análise global dos riscos dos ambientes de trabalho, como uma exigência das regras trabalhistas" (Ator-chave 4). Em relação à biossegurança, a unidade desenvolve um conjunto de ações voltadas para prevenção e minimização de riscos inerentes aos processos de pesquisa, produção, desenvolvimento tecnológico e prestação de serviços.

Os exames ocupacionais são preconizados pela NR 7 que trata do PCMSO. São eles: admissional; periódico; de retorno ao trabalho; de mudança de função; demissional. Os exames compreendem avaliação clínica, abrangendo anamnese ocupacional e exame físico, além de exames complementares.

Entre 2004 e 2005, com a criação do calendário de vacinação, o controle de vacinação relacionado com à especificidade do trabalho passou a ser uma exigência. "Após a implantação do serviço, os exames ocupacionais e a vacinação ficaram a cargo do serviço de saúde do trabalhador" (Ator-chave 8). O pronto atendimento atua tanto para casos de acidentes de trabalho quanto para situações de saúde que se apresentam durante o trabalho e atende a todos independentemente de vínculo.

Em 2003, foi implantado o programa Apoiar que tinha por objetivo implantar um sistema de acompanhamento visando subsidiar as diretrizes da instituição, assim como, proporcionar aos servidores/funcionários o apoio necessário às questões funcionais/ pessoais (Ator-chave 5 ). $\mathrm{O}$ acompanhamento aos trabalhadores se dava de duas formas: por motivo de saúde e funcional. O acompanhamento por motivo de saúde visa acompanhar os funcionários que estão afastados por licenças de médio e longo período; fornece orientações e apoio no período de licença e auxilia em sua readaptação no retorno ao trabalho. $\mathrm{O}$ acompanhamento funcional tem o objetivo de auxiliar na busca de soluções para problemas de adaptação, transferências, relações de trabalhos conflituosas, entre outros. 
O PQV foi uma iniciativa anterior ao processo de implantação do serviço. Surge acompanhando as tendências e práticas do mercado e "como uma forma de proporcionar um 'plus' aos trabalhadores” (Ator-chave 1). Oferece atividades com objetivo de promover mudanças no estilo de vida; melhorar hábitos alimentares; diminuir o sedentarismo; proporcionar maior rendimento no trabalho; evitar absenteísmo. Também é concebido como um instrumento de valorização e de melhoria de clima organizacional. O programa é compreendido como um diferencial, vinculando-se a uma imagem positiva diante do mercado (Ator-chave 6). O transporte corporativo visa ser um minimizador do estresse devido às péssimas condições de mobilidade urbana. Da mesma forma, considerou-se fundamental oferecer o café da manhã como forma de garantir uma nutrição básica. Tanto o transporte quanto a alimentação são reconhecidos como determinantes importantes para a qualidade de vida, contudo, evidenciam que "a gestão está visando também melhor pontualidade" (Ator-chave 15).

Ao se apreender a concepção de QVT buscando um link com a ST no que se refere às condições, processos e organização do trabalho, evidencia-se um distanciamento entre as concepções, pois uma apresenta proposições de mudança no estilo de vida, enquanto a outra visa à mudança nas condições de trabalho, na organização, apontando a Qualidade de Vida como um processo de gestão, em que, não só o trabalhador, mas todo um conjunto de atores e serviços necessitam atuar em uma perspectiva sistêmica, pensando na qualidade de vida do trabalhador em seu ambiente de trabalho.

\section{Avanços, desafios e proposições}

O trabalho multiprofissional é percebido como um avanço, sendo central para as práticas de ST tendo em vista a complexidade da relação trabalho e saúde. Todavia, trabalhar de forma interdisciplinar é um dos grandes desafios. O diálogo entre os profissionais com diferentes olhares permitiria uma análise mais aprofundada das questões inerentes à relação trabalho e saúde. Uma atuação interdisciplinar favorece o olhar integral, percebendo o trabalhador em todas as dimensões.

Para que se construa uma maior integração, proporcionando um comprometimento da equipe e interação com os trabalhadores, é fundamental a uniformização técnica dos saberes inerentes aos princípios da ST.

"A participação do Serviço Social e da Psicologia nos Exames Periódicos de Saúde (EPS) pode-se considerar que foi um avanço" (Ator-chave 7). Tal participação possibilita colher dados para subsidiar ações para o serviço ao utilizar instrumento para levantar elementos como condições gerais de vida, carga de trabalho, desgaste, além da motivação em relação à sua atividade e ao ambiente de trabalho. Havia uma preocupação tanto da equipe de saúde quanto da gestão em relação à possibilidade de ocorrerem situações de acidentes que demandassem uma remoção rápida e não haver um aparato suficiente para atender o trabalhador nesse momento emergencial. Apesar de terem ocorrido questionamentos quanto ao reforço e caracterização de um serviço assistencial, "houve a implantação do serviço de ambulância, que é uma conquista para os trabalhadores" (Ator-chave 14).

Um dos pontos positivos apontados por alguns atores foi o programa Apoiar conduzido pelos profissionais do serviço social e psicologia. Trata-se de um espaço de escuta e acolhimento das demandas dos trabalhadores, em que se busca a compreensão de diversas questões no âmbito das relações de trabalho e da organização do trabalho, assim como sobre o processo saúde-doença.

Em relação às diretrizes de $\mathrm{ST}$, torna-se necessário realizar periodicamente capacitação para alinhamento das práticas sob a perspectiva da ST, envolvendo a equipe de saúde, a equipe da Engenharia e Segurança e a Cipa. A uniformização de saberes na 
perspectiva da ST possibilitaria propor ações em conjunto para as questões relacionadas com os ambientes e processos de trabalho. Além disso, é preciso promover a difusão de tais princípios e diretrizes para a gestão, evidenciando a importância de incluir os saberes dos trabalhadores como parte fundamental para a tomada de decisões sobre aquilo que impacta ou não em sua saúde.

A participação dos trabalhadores como sujeitos detentores de um saber e a ampliação do diálogo entre todas as esferas são fundamentais para o alcance de práticas de saúde que, efetivamente, possam protegê-los e prevenir agravos.

A participação como ator dos processos em ações comunicativas, interdisciplinares, multiprofissionais associadas à Saúde Coletiva e trabalhando a relação do trabalho com a saúde. (Ator-chave 3).

A vigilância é um dos principais desafios, entretanto, é possível trabalhar de forma mais efetiva alguns instrumentos já estabelecidos, como o Exame Periódico de Saúde, buscando outros meios para que se estabeleça uma rotina no cotidiano do serviço.

As rodas de conversa; as visitas aos locais de trabalho; as análises nos ambientes de trabalho e suas relações (carga, desgaste, relação com chefia, pressão temporal) são instrumentos de vigilância que podem ser incorporados. (Ator-chave 2).

Uma questão que tem se intensificado devido à conjuntura estabelecida pela reestruturação produtiva é a do sofrimento psíquico e agravos à saúde mental do trabalhador (SELLIGMANN-SILVA, 2011). É preciso compreender a questão da saúde mental criando ferramentas para apontar sofrimento e tratar o problema. "Pensar criativamente alternativas e ações que possam minimante dar enfrentamento ao sofrimento psíquico articulado ao trabalho" (Ator-chave 2).

Por sua metodologia de análise de locais de trabalho, com a Ergonomia, é possível levantar dados mais precisos sobre vários aspectos da organização do trabalho e do processo produtivo, "estimulando a participação do trabalhador na busca de melhorias neste processo e nas condições de trabalho" (Ator-chave 4). A unidade atua, por enquanto, com ações pontuais de ergonomia de acordo com as demandas apresentadas. Há também que se melhorar a investigação em casos de adoecimento ocupacional, assim como participar com a Segurança do Trabalho nas investigações e no acompanhamento dos casos de acidentes de trabalho. Os dados epidemiológicos do serviço, tanto da parte médica quanto da parte psicossocial, podem ampliar a contribuição para a implementação de ações do PQV enquanto programa de prevenção e promoção à saúde e também para uma intervenção nos processos de trabalho.

Torna-se necessário construir um PQV no qual se invista em mobiliários adequados, de acordo com os padrões ergonômicos recomendados; implantar formas de gerir em que o trabalhador tenha papel fundamental para pensar seu próprio trabalho, tendo as percepções de seus riscos e o conhecimento do seu trabalho específico. Além disso, pensar ações que favoreçam a inibição de formas de gestão coercitivas e abusivas, buscando alternativas para melhorias das relações de trabalho desgastantes e adoecedoras.

Evidencia-se uma nítida linha de avanços e retrocessos desde que o serviço foi inaugurado. Essa situação, geralmente, ocorre em momentos de mudanças na gestão ou de saída de profissionais, devido a novos direcionamentos e conjuntura política da instituição. No caso específico, "a priorização de políticas internas ou ações sob uma perspectiva mais pragmática, também apresenta esse caráter de descontinuidade" (Ator-chave 16).

É necessário criar uma estrutura capaz de não ser tão vulnerável a essas mudanças de gestão e de profissionais. Uma política institucional enquanto diretriz maior, capaz 
de estabelecer propostas de capacitação que mobilize a pensar potencialidades e que sejam capazes de melhorar as interfaces. Com possibilidades de intervir nos aspectos do contrato de trabalho dos terceirizados para assegurar direitos para todos os trabalhadores, independentemente de vínculo.

\section{Considerações finais}

Constata-se, que há dificuldades em trabalhar e conceber as formas de regular o trabalho com os princípios conceituais da ST. A organização estrutural dos serviços de saúde e segurança dificultou a integração entre as áreas, ocasionando impasses no que ser refere às atribuições e enquanto uma possibilidade de fazer parte de uma interdisciplinaridade almejada pelo campo da ST. Em decorrência da separação das áreas, a unidade não possui um SESMT clássico. O que se configura é que cada área assumiu responsabilidades e buscam, apesar das visões diferentes, atender aos requisitos estabelecidos para aquilo que entendem ser em prol da melhoria da saúde e segurança dos trabalhadores.

No que tange à operacionalização, por não ter ocorrido um alinhamento sobre ST, o serviço foi concebido pelo viés pragmático da SO. O conceito de QVT com o discurso da valorização dos seus colaboradores, não do seu saber operário participativo, mas com a finalidade de retenção da mão de obra e visibilidade foi fortemente interiorizado.

É preciso esclarecer que ST e QVT, nesse caso, possuem aspectos distintos, pois a primeira busca mudanças nas condições de trabalho, enquanto a segunda se propõe a focar no indivíduo no que se refere às mudanças de hábitos e estilo de vida. Ressalta-se que é necessário não focar somente na promoção da mudança de estilo de vida, em ações terapêuticas para diminuição do estresse, ou ginástica laboral, pois, desse modo, não há interferências nos processos de trabalho e condições de trabalho. As propostas devem buscar o fortalecimento em torno da discussão dos processos de trabalho e a qualidade das relações de trabalho, em decorrência das repercussões na saúde dos trabalhadores e os impactos da organização.

Diante da complexidade dos diversos elementos apresentados, pode-se considerar que as práticas de saúde na unidade são fortemente influenciadas pelo paradigma da SO e da vertente geracional da QVT. Ainda que a Fiocruz seja um espaço de construção e disseminação de conhecimento do campo conceitual e político da ST, no cotidiano das práticas, há dificuldades para a implementação de ações sob esta perspectiva.

Apesar de alguns avanços como a constituição de um trabalho multiprofissional na execução dos EPS, ainda há muito que se avançar, havendo pouca visão integral e baixa integração das equipes, dificultando ações interdisciplinares e participativas. Além disso, existe a dificuldade de incorporar a concepção do trabalhador enquanto agente transformador da realidade que lhe causa dano. É preciso haver maior articulação entre setores intra e interinstitucionais, ações de vigilância, promover a participação e o diálogo com os trabalhadores, visando à melhoria dos processos e aperfeiçoamento das condições de trabalho. Inclui-se aqui a eliminação/minimização das relações de trabalho tensas e desgastantes.

Pode se concluir que um caminho para que as práticas de saúde no trabalho sejam executadas sob a perspectiva do campo conceitual da ST é a construção de políticas institucionais não somente abarcando o que a legislação menciona, mas também considerando as especificidades de cada instituição, avançando no conceito da ST, com todos os eixos que o campo preconiza. No caso específico, almeja-se a construção de diretrizes que estabeleçam e consolidem práticas de saúde sob a ótica da ST, para que a conjuntura ou mudanças de gestão não crie vulnerabilidades aos programas e projetos, 
proporcionando caráter de continuidade, e não de retrocessos a depender de mudanças de equipes e do contexto institucional.

É preciso criar espaços em que se favoreça uma ampla participação dos trabalhadores em todos os processos para o cuidado de sua saúde e segurança, atuando em uma perspectiva de vigilância para a consolidação do campo da ST no contexto organizacional, de modo a impactar na saúde coletiva.

\section{Referências}

ANTUNES. R. Adeus ao trabalho. São Paulo: Cortez, 2008.

BARDIN, L. Análise de conteúdo. Lisboa: LDA, 2009.

BRASIL. Constituição da República Federativa do Brasil. Brasília, DF: Edições Câmara, 2006.

Portaria $n^{0}$ 3.214, 08 de junho de 1978. Aprova

as Normas Regulamentadoras de segurança e medicina do trabalho - NR - do Capítulo V, Título II da Consolidação das Leis do Trabalho. Diário Oficial [da] República Federativa do Brasil. Brasília, DF, 1996. Disponível em: <http://www.planalto.gov.br/ccivil_03/ leis/16514.htm>. Acesso em: 10 de dez. 2014.

CAVALCANTI, C. P. N. Aspectos teórico-conceituais e históricos da construção do Campo da Saúde do Trabalhador. Im: LIMA et al. (Org.). Cadernos do Curso de Capacitação em Promoção e Vigilância em Saúde do Trabalhador para operacionalização da PASS/SIASS. Rio de Janeiro: UFRJ/Unirio, 2011.

FERREIRA, M. C. Ofurô corporativo. Brasília, DF: Universidade de Brasília, 2006. Disponível em: <http://

\section{Colaboradores}

Maria Cristina Jorge de Carvalho contribuiu substancialmente para a concepção, planejamento, análise e interpretação dos dados. Renato José Bonfatti contribuiu significativamente na revisão crítica do conteúdo. Maria Helena Barros de Oliveira participou da aprovação da versão final do manuscrito. www.unb.br/acs/artigos/at0306-03.htm>. Acesso em: 10 nov. 2014

FERREIRA, M. C.; ALVES, L; TOSTES, N. Gestão de Qualidade de Vida no Trabalho (QVT) no Serviço Público Federal: o descompasso entre problemas e práticas gerenciais. Psicologia: Teoria e Pesquisa, Brasília, DF, v. 25, n. 3, p. 319-32, jul./set. 2009. Disponível em: <http://www.scielo.br/scielo.php?pid=S0102$-37722009000300005 \&$ script $=$ sci_abstract\&tlng=pt $>$. Acesso em: 10 nov. 2014.

FRANCO, T.; DRUCK, G.; SELIGMANN-SILVA, E. As novas relações de trabalho, o desgaste mental do trabalhador e os transtornos mentais no trabalho precarizado. Revista Brasileira de Saúde Ocupacional, São Paulo, v. 35, n.122, p. 229-248. 2010. Disponível em: $<$ http://www.scielo.br/scielo.php?script=sci_arttext\& pid=S0303-76572010000200006 $>$. Acesso em: 10 nov. 2014.

LACAZ, F. A. C. Qualidade de vida no trabalho e saúde/doença. Ciência \&t Saúde Coletiva, Rio de Janeiro, v. 5, n. 1, p. 151-161. 2000.

Disponível em: <http://www.scielo.br/scielo. 
php?pid=S1413-81232000000100013\&script=sci abstract\&tlng=pt>. Acesso em: 10 nov. 2016.

O campo Saúde do Trabalhador: resgatando conhecimentos e práticas sobre as relações trabalho-saúde. Cadernos de Saúde Pública, Rio de Janeiro, v. 23, n. 4, p. 757-766, 2007. Disponível em: <http://www. scielo.br/scielo.php?script=sci_arttext\&pid=S0102-311X2007000400003>. Acesso em: 10 nov. 2014.

LIMONGI-FRANÇA, A. C.; ZAIMA, G. Gestão de qualidade de vida no trabalho. In: BOOG, G. G.; BOOG, M. Manual de Gestão de pessoas e equipes: estratégias e tendências. São Paulo: Gente, 2002. p. 78-87.

MINAYO, M. C. S. et al. Fiocruz Saudável: uma experiência institucional. Ciência \&t Saúde Coletiva, Rio de Janeiro, v. 3, n. 2, p. 151-161, 1998. Disponível em: <http://www.scielo.br/scielo.php?pid=S1413$-81231998000200014 \&$ script $=$ sci_abstract\&tlng $=p t>$. Acesso em: 10 nov. 2014.

MINAYO-GOMEZ, C. Campo da Saúde do Trabalhador: trajetória, configuração e transformações. In: MINAYO-GOMEZ, C.; MACHADO, J. M. H.; PENA, P. G. L. (Org.). Saúde do Trabalhador na sociedade brasileira contemporânea. Rio de Janeiro: Fiocruz, 2011.

MOTA, A. E.; AMARAL, A. S. Reestruturação do capital, fragmentação do trabalho e Serviço Social. In: MOTTA, A. E. (Org.). A nova fábrica de consensos. São Paulo: Cortez, 5. ed., 2010.
PAIVA, M. J.; VASCONCELLOS, L. C. F. Modelo operário italiano: o surgimento do campo da saúde do trabalhador. In: VASCONCELLOS, L. C. F.; OLIVEIRA, M. H. B. (Org.). Saúde, Trabalho e Direito: Uma trajetória crítica e a crítica de uma trajetória. Rio de Janeiro: Educam, 2011.

PINA, J. A.; STOTZ, E. N. Intensificação do trabalho e saúde do trabalhador: uma abordagem teórica. Revista Brasileira de Saúde Ocupacional, São Paulo, v. 39, n. 130, p. 150-160, 2014.

SELIGMANN-SILVA, E. Trabalho e desgaste mental: o direito de ser dono de si mesmo. São Paulo: Cortez, 2011.

TAMBELLINI, T. A.; ALMEIDA, G. M.; CAMARA. M. V. Registrando a história da saúde do trabalhador no Brasil: notas sobre sua emergência e constituição. Em pauta, Rio de Janeiro, n. 32, v. 11. p. 21-37. 2013.

VASCONCELLOS, L. C. F. Entre a saúde ocupacional e a saúde do trabalhador: as coisas nos seus lugares. In: VASCONCELLOS, L. C. F.; OLIVEIRA, M. H. B. (Org.). Saúde, Trabalho e Direito: uma trajetória crítica e a crítica de uma trajetória. Rio de Janeiro: Educam, 2011.

Recebido para publicação em agosto de 2016

Versão final em janeiro de 2017

Conflito de interesses: inexistente

Suporte financeiro: não houve 